Smith for arranging for me to see several cases under his care at the Radium Institute, and for details of these; and to Mr. Ralph Phillips for referring cases from the Deep X-ray Department at St. Bartholomew's Hospital to me, and for his valuable technical advice.

\title{
REFERENCES
}

\author{
Clapp.-Amer. Jl. of Ophthal., Vol. XV, No. 11, Nov., 1932. \\ Paton -Trans. Ophthal. Soc. U.K.. Vol. XXIX, p 37, 1909. \\ Stock.-Klin: Monatsbl. f. A ugenheilk., Vol. XLIX, p. 93, 1911. \\ Jess.-Ann. d'Ocul., Vol. CLXVI, p. 165, 1929. \\ Foster Moore.-Proc. Koy. Soc. Med., Vol. XXIV, p. 32, 1931. \\ Erggelet.-Zeitschr. f. Augenheilk., Vol. LXIV, p. 161, 1928. \\ Clapp.-Loc. cit. \\ Clapp.-Loc cit. \\ Franklin and Cordes.-Amer. Jl. of Ophthal., Vol. III, p. 643, 1920. \\ Withers.-Amer. Jl. of Ophthal., Vol. VII, p. 513, 1924. \\ Robinson.-Arch. of Ophthal., Vol. LV, p. 335, 1926. \\ Blegvad.-Acta Ophthal., Vol. IX, p. 32, 1931. \\ de Schweinitz.-Bull. of O. O. R. L. Soc., Kansas City, Mo., Vol. II, No. 4, \\ 1931. \\ 14. Desjardins.-Amer. Jl. of Roentgen., Vol. XXVI, p. 787, 1931. \\ 15. Stallard.-Proc. Roy. Soc. Med., Vol. XXVI, p. 59, 1933. \\ 16. Foster Moore, Stallard and Milner.-Brit. Ji. of Ophthal., Vol. XVI, p. 673, \\ 1931.
}

\section{SOME REMARKS ON PILOCARPINE}

BY

J. A. van Heuven, M.D.

UTRECHT

OCCASIONALLY one meets a patient suffering from chronic glaucoma, who is treated with instillation of drops of pilocarpine and complains after this of a bad and diminishing vision. Now in these cases we nearly always deal with elderly people suffering frequently from incipient opacities of the lens. More or less subconsciously, I always considered these complaints to be caused by the narrowing of the pupil. About two years ago I saw shortly after each other two very intelligent patients suffering from chronic glaucoma, who both told me very definitely that their visual acuity was lowered a good deal for one to one and a half hours after the instillation of a 2 per cent. solution of pilocarpine.

Controlling this statement it appeared that indeed the vision was decreased from one-third to one-fourth of what it was before, about a quarter of an hour after the instillation of 2 per cent. pilocarpine solution in the conjunctival sac. It took one and a quarter to one and a half hours before it was normal again. In 
both cases there was not the slightest opacity in the centre of the lens, and in both pilocarpine did its work beautifully, as with the aid of it their intra-ocular tension become normal.

Discussing this phenomenon with him, Professor Weve showed me a paper of C. Hess, ${ }^{*}$ containing a very good description of this phenomenon.

Hess found that after putting one drop of 2 per cent. solution of pilocarpine or eserine in his own conjunctival sac his vision decreased from one-third to one-half. This lasted for one to two hours. At the centre of clearest vision a greyish yellow spot appeared. On looking at the sky he saw centrally a number of
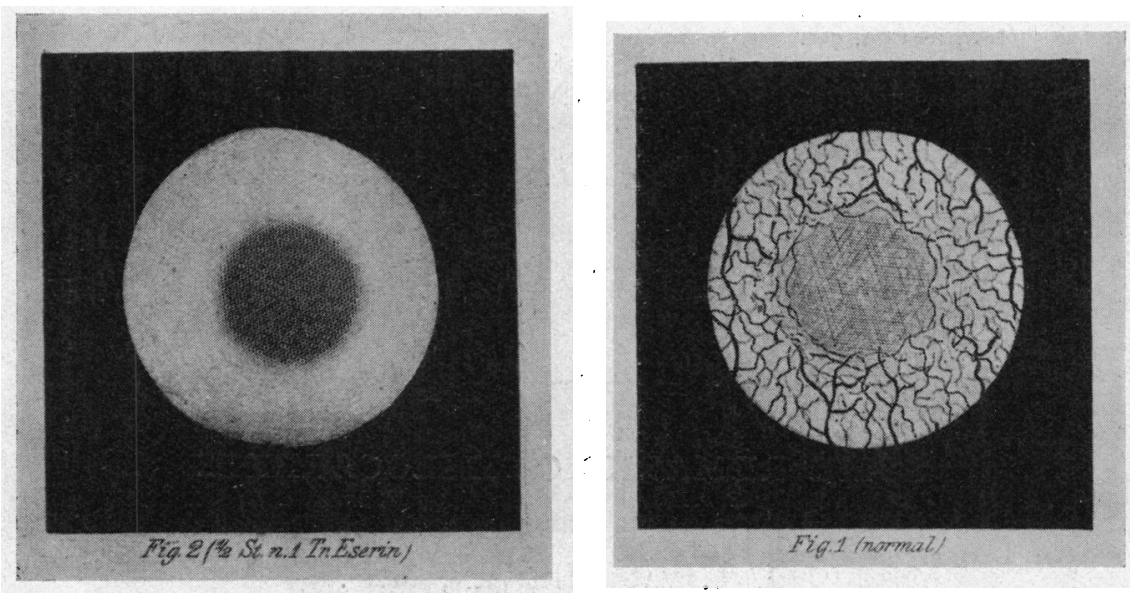

dark spots partially joining each other. On looking in the dark the first moment the same figure was seen bright on the dark background. When the picture formed by the vessels of the fundus was made visible by moving a stenopaeic slit in front of the pupil, it was evident that, about 12-15 minutes after the instillation of pilocarpine, the circumfoveal capillaries became less clearly visible and that a little later they disappeared totally.

In the region of the foveal "chagrin" a compact mass of small dark globules was seen. After one and a half to two hours the normal entoptic picture came back almost suddenly.

On using a 1 per cent. solution the phenomenon appeared later and lasted shorter, on using a 0.5 solution nothing was seen. Instillation of a 1 per cent. solution of homatropine about one to two hours previously inhibited the phenomenon. In trying to explain this phenomenon, Hess excluded the influence of the width of the pupil and that of a temporary rise of the tension. He

*Arch. f. Augenheilk., Bd. 86, Heft 1/2, pp. 89-98,1920. 
considers it to be due to a direct action of pilocarpine on the middle layers of the retina. This may either be a spasm of the capillaries or an opacity in the retina. In Hess's paper the following pictures are found illustrating his sensations.

I have looked at this problem from various angles. First every patient using pilocarpine was regularly asked about his subjective sensations after the instillation of it. The quite typical complaints of this relative central scotoma can be easily differentiated from the vast number of ordinary complaints. In the course of one and a half years I was fortunate enough to find four typical cases which showed objectively a relative central scotoma after the instillation of pilocarpine.

Case 1.-A man, aged 53 years, glaucoma simplex, O.D.S. Tension varies after instillations of 2 per cent. pilocarpine thrice daily between $25-30 \mathrm{~mm}$. Hg (Bailliart). V..O.D.S. 6/6, after correction of the small amount of hypermetropia. 15-20 minutes after instillation of pilocarpine the vision is decreased to $6 / 18$ in each eye. One and a half hours later everything is normal again.

Case 2.-A man, aged 57 years. O.D. anophthalmos, O.S. glaucoma simplex. Instillations of 2 per cent. pilocarpine four times daily keep the tension of the left eye about normal.

V.O.S. is $6 / 12$. Some very small opacities in the periphery of the lens. One single posterior synechia. A quarter of an hour after pilocarpine the vision is lowered to $6 / 24$, an hour later it is normal again.

Case 3.-A man, aged 62 years. O.D.S. glaucoma simplex. V.O.D. 6/36, V.O.S. $6 / 6$ after correction of the hypermetropia. Pilocarpine given to the left eye causes a decrease in the vision to $6 / 18$; not before one and a half hours afterwards is the vision normal again.

Case 4.-A woman, aged 61 years. O.D.S. glaucoma simplex. In the right eye there is only an eccentric vision of $1 / 60$, in the left eye after correction of the hypermetropia the vision is $6 / 8$, after pilocarpine $6 / 24$, one to one and a half hours later $\dot{6} / 8$ again.

These four patients agree in this respect that they all are above 50 years of age, and I may add at once that during two and a half years of my observation of this phenomenon, I have never seen a young person showing this relative central scotoma after pilocarpine. Possibly this could also be explained by the fact that in young people the use of pilocarpine is very seldom necessary.

I instilled in the conjunctiva of 30 students from 20-30 years of age drops of solutions varying from 2 to 6 per cent. of pilocarpine. The slightest sensation of a relative central scotoma was never found.

When turning back to our four patients, we take their visual fields for white and for colours and also their blind spots at 1 metre 
distance, it appears that no alteration in these values is found. This, however, is not always the case.

Let me first stress the point that I am always very careful in proving anything by a method as subjective as the examining of the visual field or the blind spot. But considering these values as a link in a chain of symptoms they are valuable.

During the month of January, 1932, I saw a patient (case 5), a man, aged 49 years, suffering from chronic glaucoma in both eyes, having a tension of about $35 \mathrm{~mm} . \mathrm{Hg}$ without any treatment. Instillation of a 2 per cent. solution of pilocarpine thrice daily

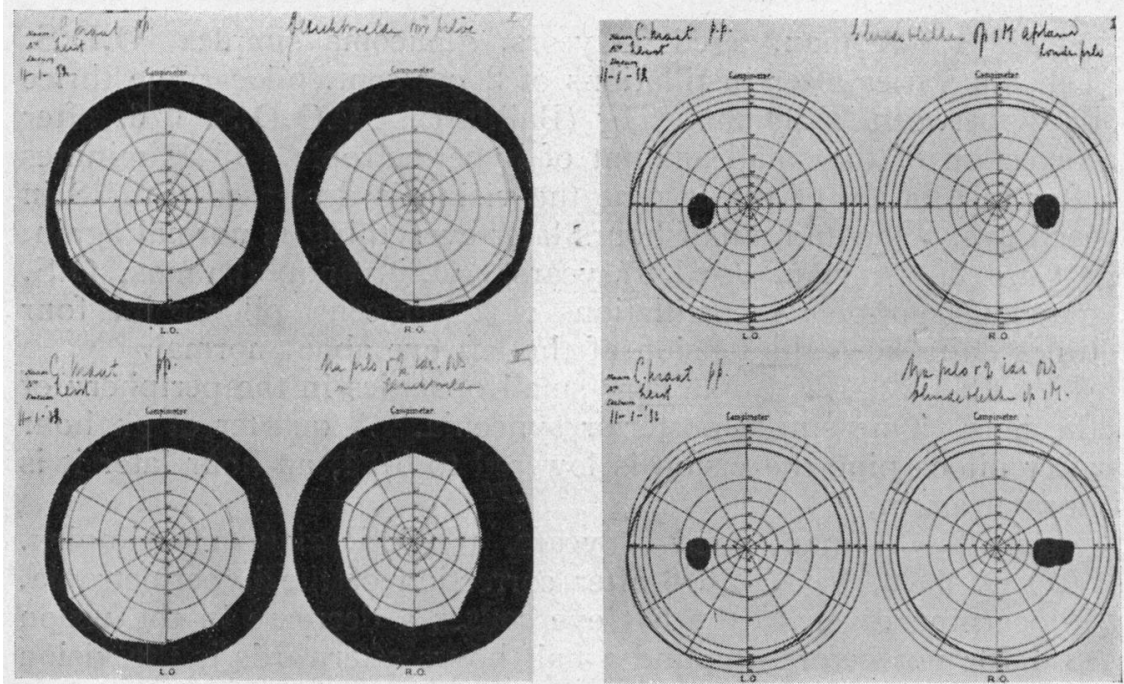

gave the beautiful result that the tension in both eyes kept below $25 \mathrm{~mm}$. Hg. This patient did not complain of the relative central scotoma as described above.

The visual fields and blind spots, taken after instillation of pilocarpine were a little bit suspect, which is shown in the following pictures. There was no alteration for red and blue.

That the next patient, case 6 , showed very remarkable alterations after the instillation of pilocarpine was without any doubt. I had his fields taken by different people both before and after the instillation of the drops and always got similar results.

Looking at the latter pictures one is inclined to think of a spasm of the vessels. I have tried to confirm this suspicion by experiments made first on a dog, later on, on rabbits.

Firstly an iridectomy was performed and at the same time the membrana nictitans was removed. By doing so we are able 


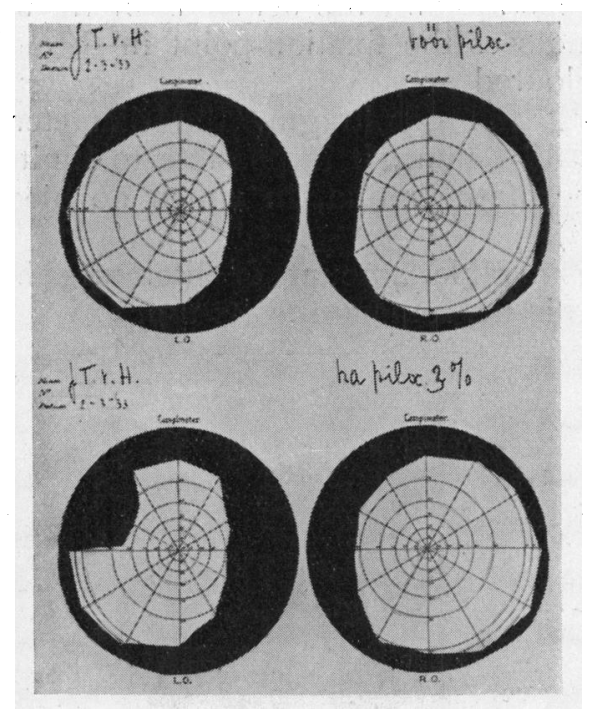

to give pilocarpine and at the same time it remains possible to look at the fundus with an ophthalmoscope and even to make a photographic picture of it. Now the lethal dose of pilocarpine hydrochloride is found to be $0.12-0.23$ grams intravenously injected in rabbits. In dogs it is considerably less. The. minimal dose which causes vomiting is 0.7 milligram pro $\mathrm{Kg}$.

After having them prepared in the manner described above I injected in one dog and nine rabbits pilocarpine hydrochloride, increasing the dose until serious symptoms appeared. Sometimes it was possible to save the animal by an injection with atropine, but in that case, of course, the experiment of the day was spoiled. The result of these experiments was discouraging. The changes in the vessels of the fundus which were sometimes found were so uncertain that they are not worth discussing.

After this I examined my patients with Scheerer's entoptoscope. This instrument has been built for the subjective examination of the blood-current in the capillaries of the retina. On looking through it the red blood-corpuscles are distinctly seen as luminous rods on a bluish-violet background. As this phenomenon shows itself differently in different conditions of the eye, it may be useful for clinical purposes.

The instrument itself has been built up from an ocular, an iris diaphragm, a blue-violet filter, which only permits rays of a wavelength under 4,600 angström to penetrate, a condenser, and an electric bulb of 100 watt; which pieces are suitably mounted on a stand. 
In using the instrument, the ocular is firstly focused in such a manner that one sees the fixation-point in the midst of the field without any coloured area.

By narrowing the diaphragm, the diameter of which can be varied from 18-1 mm., it is possible to limit and to measure the central zone of the retina, in which no bloodstream is seen (Maxwell's spot).

Quite a considerable amount of literature has been written already about this instrument and its use.

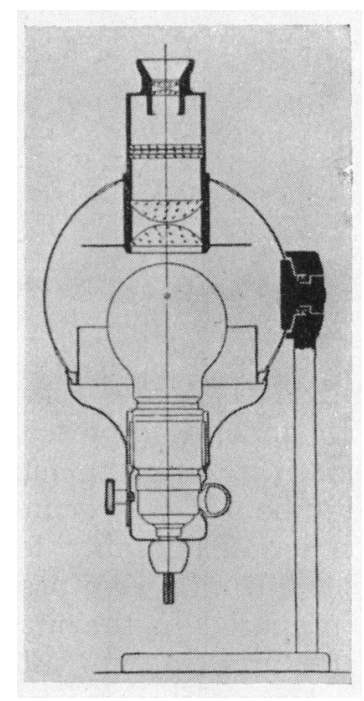

Scheerer ${ }^{1}$ thinks that the phenomenon actually must be localized in the pre-capillary arterioles and that it is caused by total reflection of the red corpuscles, which become self-luminous.

F. P. Fischer ${ }^{2}$ localizes the phenomenon in the capillaries and considers it to be caused by shadow-formation. He is very likely right in both considerations.

Gesker $^{3}$ was able to measure the apparent size of the centre of the macula, which was free from vessels. His opinion, that the movements seen must take place in the outer nuclear layer, is shared by Abelsdorff and Nagel.

Only by mechanical pressure the frequency and rhythm of the phenomenon can be altered, not by general or local intoxications.

Horniker $^{4}$ is of the same opinion. It is he also who lays stress on the importance of measuring the size of Maxwell's spot, by means of the diaphragm.

The values thus obtained fit in with a theory of pathology 
and physiology of the capillary system, according to Ricker, O. Müller and his school. They take it for granted that these facts show a separate innervation of the macula.

Examining different patients with the aid of the entoptoscope I have been able to control and confirm the observations, made by these different authors. It appears to be evident-as has already been pointed out by Fischer - that even quite normal individuals do not always make identical observations and also that the phenomenon is observed differently on different occasions. But-and this is important-in those persons, who are getting relative central scotomata after the instillation of drops of pilocarpine, the phenomenon presents itself clearly without exception.

So I examined my patients, whose details I have given above, with this entoptoscope. They all agreed in telling me spontaneously that after the instillation of drops of pilocarpine they observed quite a remarkable slowing down of the blood-current, which in every case was followed by an enlargement of Maxwell's spot. Increasing during the first quarter to half hour after the instillation of pilocarpine, these phenomena disappeared after one hour. So their course was parallel to that of the diminishing of vision.

One question now became acute: "Can anything be done to prevent this supplementary action of pilocarpine?" I have much pleasure in being able to answer: "Certainly, and even in two ways."

First let us consider a patient, who is bound to take drops of a 2 per cent. solution of pilocarpine thrice daily and in doing so, suffers from a relative central scotoma, as described above.

If one makes him take at the same time thrice daily 0.005 grams of solutio nitroglycerini by the mouth, the relative central scotoma will not appear whilst pilocarpine still acts as usual, especially in regard to its action of lowering the tension of the eyeball.

Solutio nitroglycerini contains 1 per cent. of nitroglycerine, dissolved in 90 per cent. alcohol. Small doses of nitroglycerine, such as mentioned above appear to be quite harmless. Nitroglycerine, however, also appears to act specifically on certain groups of small vessels, which possibly might give an explanation of its action in our case.

Secondly one gets the same result, namely the full action of pilocarpine without any supplementary action, if one adds just a little cocaine to the solution of pilocarpine.

After a series of experiments I take it for granted that a solution of 2 per cent. pilocarpine hydrochloride equals a solution containing : 1 per cent. pilocarpine hydrochloride, $0 \cdot 3$ per cent. eserine hydrochloride and 0.5 per cent. cocaine hydrochloride. In those patients who suffered from relative central scotoma, this supplementary action disappeared on substituting the above mentioned 
mixed solution for the usual 2 per cent. solution of hydrochloride of pilocarpine. The following curve shows, however, clearly that the beneficial action of lowering the intra-ocular tension is not at all interfered with.

The curve shows the intra-ocular pressure of a man, aged $5 \pi$ years, badly suffering from glaucoma simplex, which had caused total blindness of the right eye and had left him a visual field in the left eye, whose margin nearly reached the centre. Only instillations of a 2 per cent. solution of pilocarpine as much as six times daily

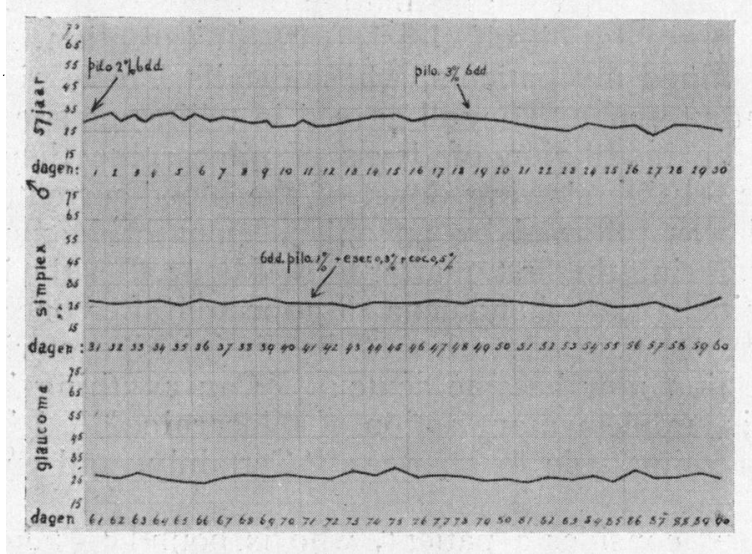

could keep his intra-ocular tension about normal. His intra-ocular tension was controlled daily, often more than once. On the 19th day of the curve pilocarpine was changed into drops of the mixture of pilocarpine-eserine-cocaine. The curve shows no alteration at all, though the patient was under control for a considerable period (90 days).

A second curve shows the same in a man, aged 55 years, whose intra-ocular tension also behaved similarly after changing his

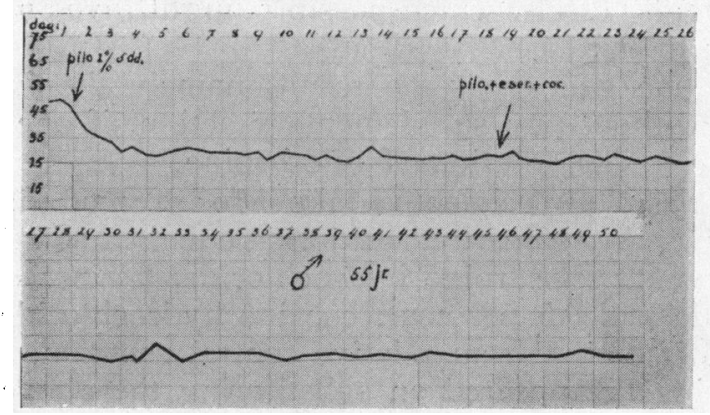


pilocarpine drops into drops of the above mentioned mixture. Neither of these two patients suffered from a relative central scotoma and the mixture drops were used only to demonstrate their effect on the intra-ocular tension and to make comparison with the effect, obtained by pilocarpine.

\section{Summarizing I can say :-}

1. Occasionally one meets with a patient, of middle or advanced age, who complains after the instillation of drops of pilocarpine of a temporarily serious diminution of vision. This is caused by a spasm of the capillaries in the region of the fovea centralis retinae, as has already been described by Hess.

2. Experiments on animals to prove this, have failed.

3. By using the entoptoscope of Scheerer this phenomenon can be investigated and confirmed beautifully.

4. The action of pilocarpine of lowering the intra-ocular tension remains the same, when one gives at the same time small doses of solutio nitroglycerini to the patients by the mouth, but the relative central scotoma-if present-disappears.

5. The same effect can be obtained by changing the pilocarpine drops into drops containing a mixture of pilocarpine-eserinecocaine. In doing so the equation " 2 per cent. pilocarpine solution is equal to a solution of 1 per cent. pilocarpine plus 0.3 per cent. eserine plus 0.5 per cent. cocaine" appears to hold good.

\section{REFERENCES}

1. Scheerer, R.-Die entoptische Sichtbarkeit der Blutbewegung im Auge und ihre klinische Bedeutung. Klin. Monatsbl.f. Augenheilk., Bd. LXXIII, p. 67, 1924.

2. Fischer, F. P.-Beobachtung und Beeinfluszung des Blutkreislaufes in der Retina. Klin. Monatsbl. f. Augenheilk., Bd. LXXIV, Jan.-Febr. H., S. $220-221,1925$.

3. Gesker, Lulius.-Over de physiologie van het entoptisch zien der bloedbeweging in het oog (Universitäts-Augenklinik, München). Arch.f. Augenheilk., Bd. XCVI, H. 3/4, S. 419-31, 1925.

4. Horniker.-Airch. f. Ophthal., Vol. CXXIII, pp. 286-360, 1929. 